Loading

The Journal of the Canadian Game Studies Association

\title{
"No one gives you a rulebook to raise a kid": Adoptive Motherhood in The Walking Dead Video Game Series
}

\section{Sarah Marie Stang}

Volume 12, Number 20, Fall 2019

URI: https://id.erudit.org/iderudit/1065897ar

DOI: https://doi.org/10.7202/1065897ar

See table of contents

Publisher(s)

Canadian Game Studies Association

ISSN

1923-2691 (digital)

Explore this journal

Cite this article

Stang, S. (2019). "No one gives you a rulebook to raise a kid": Adoptive

Motherhood in The Walking Dead Video Game Series. Loading, 12(20), 51-70.

https://doi.org/10.7202/1065897ar

\section{Article abstract}

This article closely examines the representation of adoptive motherhood in Telltale Games' The Walking Dead video game series. It builds off previous research which has examined The Walking Dead: Season One as an example of a 'dadified' game to explore the ways adoptive motherhood is represented throughout the series. More specifically, this article focuses on the series' protagonist, Clementine, as she develops from a daughter-figure to a mother-figure. Overall, this article argues that although TWD has been discussed primarily as a dadified game and much of the extant literature on the series has focused on Lee as a father-figure, TWD series can also be read as a 'momified' narrative. While there are several problematic aspects in the way Clementine is portrayed, the series is notable in that it explores adoptive maternity, centralizes the experiences of non-white characters, and reinforces the message that family is not limited to blood relations. Because of its centralization of Clementine - a young, potentially queer, adoptive mother of colour - TWD series should be considered as a maternal narrative, rather than only categorized as another dadified series.
This document is protected by copyright law. Use of the services of Erudit (including reproduction) is subject to its terms and conditions, which can be viewed online.

https://apropos.erudit.org/en/users/policy-on-use/ 


\title{
"No one gives you a rulebook to raise a kid": Adoptive Motherhood in The Walking Dead Video Game Series
}

\author{
Sarah M. Stang \\ York University \\ smstang@yorku.ca
}

\begin{abstract}
This article closely examines the representation of adoptive motherhood in Telltale Games' The Walking Dead video game series. It builds off previous research which has examined The Walking Dead: Season One as an example of a 'dadified' game to explore the ways adoptive motherhood is represented throughout the series. More specifically, this article focuses on the series' protagonist, Clementine, as she develops from a daughter-figure to a mother-figure. Overall, this article argues that although $T W D$ has been discussed primarily as a dadified game and much of the extant literature on the series has focused on Lee as a father-figure, TWD series can also be read as a 'momified' narrative. While there are several problematic aspects in the way Clementine is portrayed, the series is notable in that it explores adoptive maternity, centralizes the experiences of non-white characters, and reinforces the message that family is not limited to blood relations. Because of its centralization of Clementine - a young, potentially queer, adoptive mother of colour - TWD series should be considered as a maternal narrative, rather than only categorized as another dadified series.
\end{abstract}

\section{Author Keywords}

The Walking Dead; motherhood; adoptive; parenthood; dadification; fatherhood; zombie; family; representation

\section{Introduction}

Telltale Games' critically acclaimed and commercially successful point-and-click adventurestyle video game series, The Walking Dead (henceforth $T W D$ ), is adapted from the comic book series of the same name created by Robert Kirkman. ${ }^{1}$ The story focuses on human survival after a zombie outbreak has wiped out most of the human population. TWD: Season One has been the subject of games scholarship exploring its approach to morality and player choice (Bell, Kampe, \& Taylor, 2015a; Smethurst \& Craps, 2014; Sulimma, 2014); its nuanced and nonhypermasculine portrayal of black paternal masculinity (Bell et al., 2015b; Bennett, 2018); and the caring, nurturing father-daughter relationship that develops between the first season's main characters, Lee and Clementine (Stang, 2016b, 2017, 2018; Voorhees, 2016). While this research has constituted an important contribution to game studies, it has focused exclusively on the first game in the series. In this article, I build off this work but expand the focus to discuss the series 
as a whole and shift the focus away from fatherhood to motherhood, examining how Clementine develops from a daughter-figure to a mother-figure throughout the series.

Research for this article involved close reading methods, with gameplay recordings, screenshots, and detailed notes taken during and after play sessions used for reference. Through this examination, I demonstrate that although $T W D$ has been discussed primarily as a 'dadified' game and much of the extant literature on the series has focused on Lee as a father-figure, TWD series can also be read as a 'momified' narrative. Clementine is centralized throughout the series, as she is the only character to appear in all four seasons and is the player-character in two of them, and its narrative focus is on her becoming and then developing as a mother-figure. In this sense, $T W D$ series is a rare example of a maternal video game narrative. While there are several problematic aspects in the way Clementine is portrayed, the series is notable in that it explores adoptive maternity, centralizes the experiences of non-white characters, and reinforces the message that family is not limited to blood relations. This article therefore argues that while it should not be uncritically celebrated, $T W D$ series offers an alternative and more diverse portrayal of familial bonds than is found in most video games. Because of its centralization of Clementine - a young, potentially queer, mother of colour - as both a video game non-player character (NPC) and player-character (PC), TWD series is important to consider in terms of diverse representation and serves as a rare example of a maternal video game narrative.

\section{Context: Clem and Lee in The Walking Dead: Season One}

In TWD series, player choice in the context of dialogue with NPCs is the basis for most of the gameplay, though players are also tasked with exploring, picking up useful objects, and fighting zombies and other enemies through aiming and shooting/hitting or through rapid button pushing based on on-screen prompts - known as quick time events. The unique selling point of these games (referred to as 'seasons') is that "the story is tailored by how you play" - in other words, the choices made by the player will impact the narrative (TWD). The player is usually given a choice between two or four options, with only a matter of seconds to input their response (see Figure 1). In dialogue, one of the four options is always silence, which is the default response if the player takes too long to decide. After the player makes a choice, the games often remind them that "this action will have consequences" or that a specific character "will remember that" $(T W D)$. Given the serious and emotionally-charged setting of a violent zombie apocalypse, many of the choices players must make include choosing who to save, making tactical plans and survival decisions, convincing people to trust their character or let them live, and mediating conflicts in order to keep the group of survivors from killing each other. 


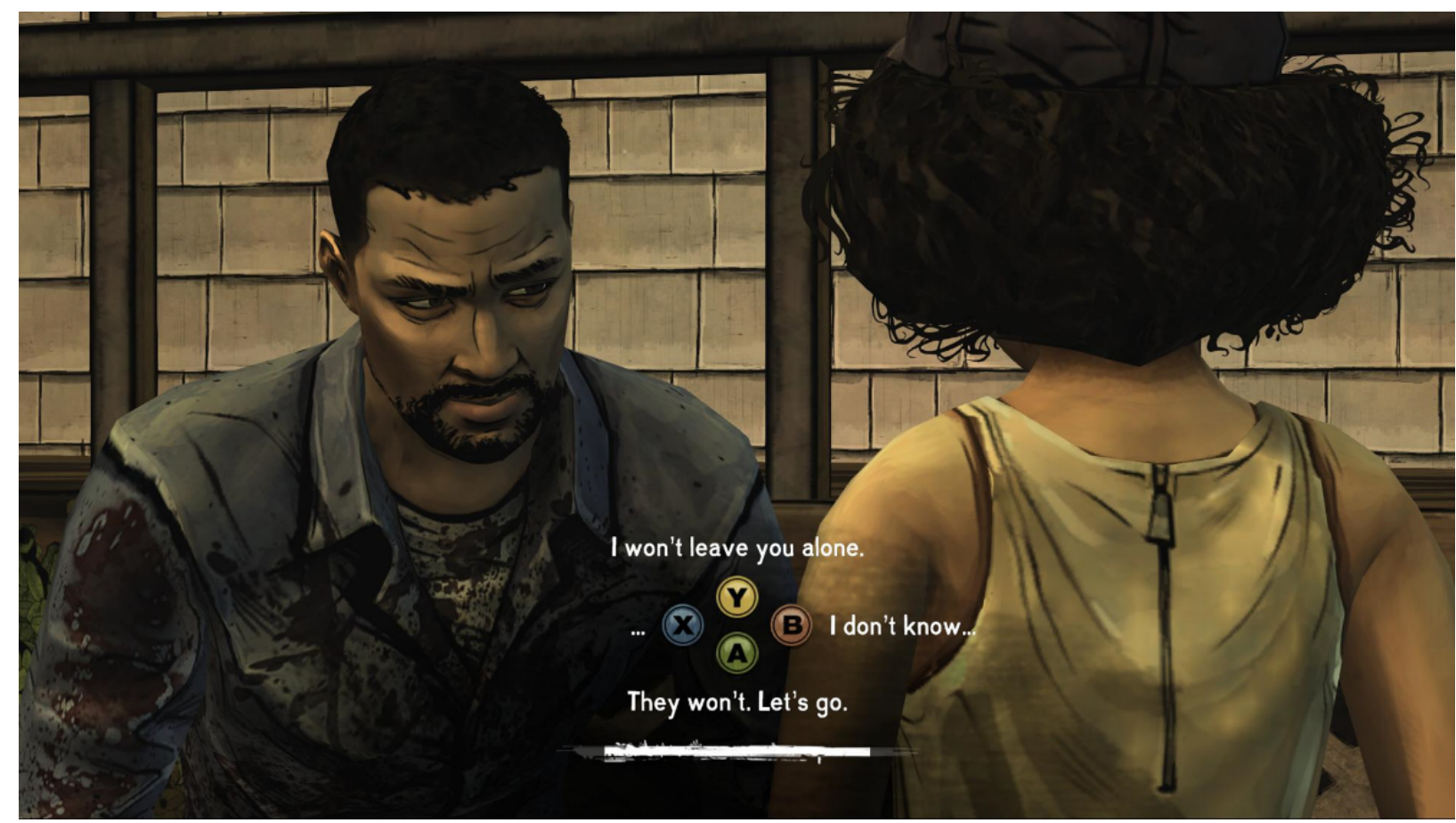

Figure 1: Lee and Clem. Screenshot taken from The Walking Dead: Season One

Despite the ominous warning that "this action will have consequences," TWD series follows a branching decision tree format in which the narrative splits based on player choice and then converges again at specific points in the game. At the end of each episode, players are shown statistics comparing their decisions to those made by other players, such as "you and $68 \%$ of other players chose to save Carley" (TWD). While violence is certainly ubiquitous in the series, it is not the focus of gameplay. Unlike many zombie-themed video games, TWD is primarily about managing interpersonal relationships and making difficult survival decisions. This microcosmic focus follows the theming of the comic, as Kirkman observes of his creation, "the only thing that's really special about The Walking Dead is the human characters and the narrative that they exist in" (Reeves, 2012, para. 3).

In TWD: Season One (hereafter $S 1$ ) the player-character is Lee Everett, a university professor recently convicted for murdering a senator. Lee escapes his police transport in the chaotic aftermath of the zombie outbreak and encounters an eight-year-old girl named Clementine (Clem). Clem had been hiding in a treehouse in fear of her zombified babysitter, so Lee rescues her and accompanies her on a journey to find her missing parents. Lee quickly becomes a fatherfigure to Clem: he comforts her, teaches her how to survive, and protects her at all costs. Melissa Hutchison, the voice actor for Clem, remarked that "the whole backbone of the story is the relationship between Lee and Clementine, and the choices Lee makes in order to protect Clementine" (Wallace, 2012, para. 13). Clem's relationship with Lee is more impactful for her than her relationship with her biological parents: throughout the following games in the series, when asked about her family and the people she loved, Clem always brings up Lee and rarely discusses her biological parents except to mention that they are deceased. 


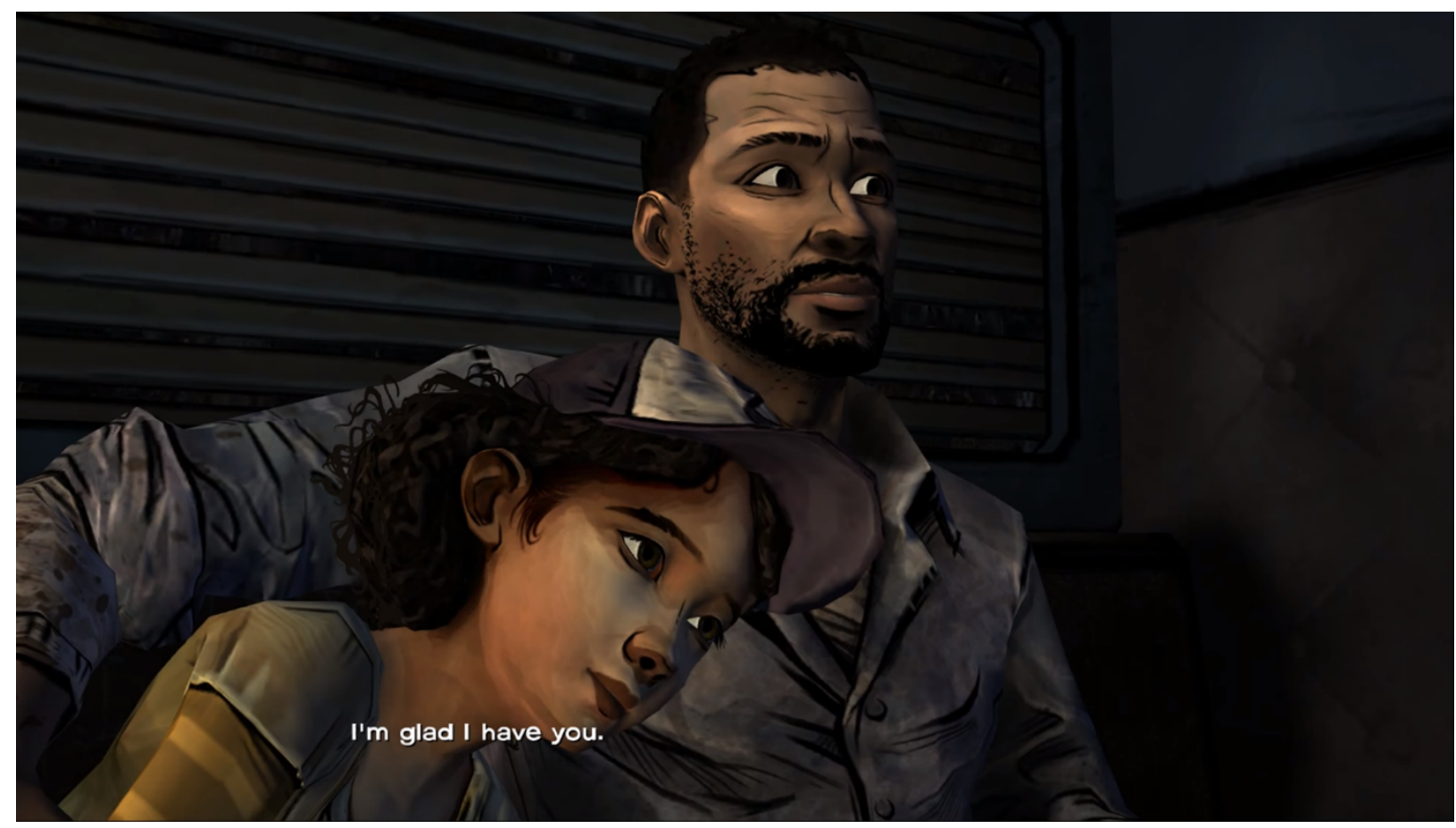

Figure 2: Lee and Clem. Screenshot taken from The Walking Dead: Season One

The game makes it clear that Lee's primary motivation is to protect Clem. While she never refers to Lee as her father, Clem does rely on him, trust him, and is physically affectionate towards him. Lee's relationship with Clem is also noteworthy because even if the player consciously tries to make Lee act aggressive or cold towards her in each dialogue and action choice, most moments of paternal care are not optional. In this sense, the game forces players to enact a form of caring tenderness, thereby dictating the nature of Lee and Clem's relationship even within a choice-heavy narrative (Bell, Kampe, \& Taylor, 2015b). This separation of parental care from biological connection - that is, the message that your parent can be someone you choose rather than a blood relative - is established in the very first instalment and returns as a theme throughout the rest of the series.

As previously mentioned, several game scholars have focused on the relationship between Clem and Lee in their analyses of the first season. Toby Smethurst and Stef Craps (2014), for example, have argued that $S 1$ draws the players into the game by making them care deeply about the characters and feel responsible for what happens to them (p. 11-12). Kristina Bell, Nicholas Taylor, and Chris Kampe (2015a \& 2015b) conducted microethnographic studies of players, finding that they often demonstrated moments of close identification with Lee (2015a) and took on the role of protective, caring father-figure, regardless of their own gender identity (2015b). Players therefore enacted a mature parental identity as they began to identify with Lee, focus on caring for Clem, and "express emotional openness, patience, compassion, and selflessness" (2015b, p. 15). The rest of the seasons follow this affective approach and are successful at encouraging the players to care deeply about the main characters. Clem is a particularly important character for several reasons: first, players begin to care about her from the very beginning of the first season, as discussed above; second, she reappears throughout the series as a main character; and third, she is centralized as the player-character in two of the four seasons. 
In this sense, Clem can be read as the series' main protagonist, even when she is not the playercharacter.

\section{The Walking Dead as a Dadified Game}

Maria Sulimma (2014) analysed $S 1$ in terms of its "alternative take on the theme of parenthood" - a theme which is central in the comics as well as the television adaptation (p. 84). As Sulimma observed, "the central question that parent figures raise in these narratives is whether they should try to protect and shelter children or teach them to survive on their own in an apocalyptic world an undertaking fraught with morally ambiguous consequences" (p. 87). Throughout the first season, several characters assume Lee is Clem's biological father, or directly ask him if he is. Based on their reactions to finding out that Lee is not Clem's biological father, Sulimma argued that other characters in the game view surrogate fatherhood as less legitimate than biological fatherhood. She pointed out that several older, white male characters continuously tell Lee - a black man - what to do with Clem (who is also non-white) and suggest she is not safe with him. These older white men, according to Sulimma, represent pre-apocalypse patriarchal hierarchies and privileges (p. 88). In this sense, these other characters "present themselves as rivals to Lee's status of surrogate father, as they claim to know better how to provide for Clementine" (p. 88). Female characters also criticize Lee's parenting, offering advice and saying that they hope he knows what he is doing with her, however, many of the female characters seem to trust Lee more due to his relationship with Clem. For example, when Lee tries to take the blame for stealing supplies to diffuse a tense situation, another character, Lilly, does not believe he would steal their supplies with a child in his life. In other words, Lee is perceived as a better person because he has Clem to protect. These themes - that is, the questioning and doubt directed at non-biological parents and the assumption that people behave in certain ways if they have a child to protect will return in later seasons.

Sulimma also emphasized the importance of specific scenes of parental care in $S 1$, especially the scene in which Lee cuts Clem's hair so that it cannot be easily grabbed, then teaches her to shoot a gun. This moment of non-optional teaching is mentioned by other scholars as well (Bell et al., 2015b; Stang, 2017) and is referenced in subsequent instalments in the series, underscoring its importance as a formative moment for Clem, especially as she takes on the role of teacher/parent herself. However, in post-apocalyptic narratives in which survival is the most important thing, moments of tenderness and care without purpose are rare. In several post-apocalyptic games, father-figures are tasked with teaching their children how to survive without them, so this scene actually cements Lee's paternal role as father-teacher. This is paralleled in later dadified postapocalypse games like The Last of Us (Naughty Dog, 2013), with Joel teaching Ellie to fight and survive; Horizon Zero Dawn (Guerrilla Games, 2017), with Rost teaching Alloy to hunt and fight; and God of War (Santa Monica Studio, 2018) in which Kratos teaches his son Atreus to be a man, to fight, and to survive.

Although these scenes of paternal teaching are found in several games, Bell et al. (2015b) have argued that this moment is particularly tender in $S 1$, emphasizing the uniqueness of $S 1$ as a video game. This is especially apparent when Lee is compared to the paternal protagonists in games like BioShock Infinite (Irrational Games, 2013) and The Last of Us: 
In contrast to the violent, ruggedly individualistic and hegemonically masculine fathers offered by these games, TWD rewards a fatherhood rooted in non-violence, nurture, and self-sacrifice - gendered characteristics that are commonly categorized as feminine, yet are essential for a father to raise an emotionally and behaviorally healthy child.

p. $15(2015 b)$

Gerald Voorhees (2016) also compared S1 with BioShock Infinite and The Last of Us, arguing that while it is a violent game, it offers a healthier and more nuanced father-daughter relationship - a portrayal even more remarkable for being between two characters of colour in a medium notorious for lacking, stereotypical, and offensive representations of racialized characters.

Specifically, Voorhees (2016) discussed $S 1$ in the context of dadified games, a term that points to "the increasing prevalence of digital games in which the player is positioned in the role of a father/father figure" (para. 1). This idea originally came from games journalist Stephen Totilo (2010) when he celebrated this trend - what he called the 'daddening' of video games - as a maturation of the industry. He claimed that the centralization of father-figures is "an effective method for getting the player to feel something" (par. 13). On the other hand, game critics and scholars have critiqued what they label as the 'dadification' of video games as simply another means for developers to valorize violent male agency (Brice, 2013; Joho, 2014; Myers, 2013; Stang, 2016a, 2017, 2018; Voorhees, 2016). Indeed, these dadified protagonists are often tasked with protecting a mostly passive, victimized daughter-figure, with mother-figures absent, deceased, or vilified. As such, these games support traditional notions of masculinity grounded in uncompromising protectiveness while also humanizing their violent male protagonists by turning them into fathers who will do anything to protect their daughters. While heroic paternal power fantasies are popular across media, these video game fathers are particularly problematic because their paternity becomes obsessive and toxic (Myers, 2013) and they are often granted control over their daughters' fates (Joyce, 2014; Stang, 2016a; Walker, 2013).

Totilo's (2010) argument that fatherhood is the way to get "the player to feel something" (par. 13) is not a new one. Hollywood films, for example, have centralized paternal narratives for decades in order to get their audience to "feel something." This seems to be particularly true in films set in violent, hostile worlds in which fathers must fight to protect their children. Indeed, in her research on paternal postfeminism in Hollywood cinema, Hannah Hamad (2013) argued that there has been a recent "cycle of paternalized narratives of social disintegration and apocalypse" that often "centralize protectorate fatherhood in narratives that place fathers and their children in extreme and exceptional circumstances" (p. 109). According to Hamad, action films like Signs (2002), Minority Report (2002), or War of the Worlds (2005) support a return to traditional notions of "masculinity centred upon uncompromising protectiveness" (p. 110). Importantly, as Yvonne Tasker (2008) noted in her study of male parenting in contemporary cinema, "the centring of the male subject is typically achieved at the cost of women, with mothers marginalised or even absent from various father-centred films" (p. 176). Indeed, mothers are often absent or deceased in post-apocalyptic paternal narratives - conveniently removed to allow for the centralization of the father's story. 
However, this trend may be shifting in film and television, as A Quiet Place (2018) demonstrates that not only do mothers also protect their children, but siblings protect each other, and children can also save their parents. In that film, the father sacrifices himself to save his children, and the mother becomes the parent who embodies "uncompromising protectiveness." While paternal sacrifice is certainly a narrative trope in games (like the BioShock series [Irrational Games, 20072013] especially - for more on this see Blythe Adams, 2018; Stang, 2018), that sacrifice usually leaves the child an orphan, as the mother is already dead or absent. In Bird Box (2018), another post-apocalyptic thriller film, a mother must escort her two young children to safety in a world full of invisible, horrific monsters. The Handmaid's Tale (2017-ongoing) television series is also an example of a survival narrative - this time more dystopian than post-apocalyptic, but in that same vein - that focuses on motherhood rather than fatherhood. Similarly, the post-apocalyptic film Mad Max: Fury Road (2015) centralizes mothers and even vilifies fathers. All these productions tie maternity with survival, with characters pregnant, giving birth, and caring for babies and children in extremely violent, hostile, and dangerous conditions. However, while maternal narratives are perhaps becoming more common in film and television, they are rarely centralized in games. Indeed, the trend of dadification has become so popular that some critics have demanded to know why there are so few mother-figure protagonists in games to balance it out, and why maternal characters are portrayed so poorly - that is, as villains, monsters, or victims - when they are present (Campbell, 2016; Gray, 2017; Smith, 2014). This discussion points to an important reason for which $T W D$ series is remarkable: Clem is the player-character in the second season, in which she becomes a mother, and again in the fourth (and final) season, in which her maternal role is more fully explored.

\section{The Walking Dead: Season Two and A New Frontier (in which Clem becomes a 'natural' mother)}

Sulimma (2014) identified Clem as an example of a 'damsel in distress' character, since she primarily exists in $S 1$ to be protected by the player-as-father-figure. Bell et al. (2015b), on the other hand, argued that Lee is more than simply a protector of a damsel in distress, rather he is teaching Clem how to survive in a hostile world without him. Indeed, Lee is bitten by a zombie at the end of the first game, and Clem is forced to either shoot him or watch him die and reanimate as a monster. This is shortly after Clem learns that her own parents have both become zombies, so she has lost all her parental figures. Until, that is, she reunites with Kenny in Season Two (hereafter S2). Kenny was a central character in the first season, and his reunion with Clem places him in a surrogate father role - he even accidentally calls her by the name of his deceased son - though he is a temperamental and toxic companion. $S 2$ sees Clem fighting to survive in a hostile world, dealing with her fraught reunion with Kenny, and developing relationships with new - though ultimately untrustworthy - characters.

In the final episode of $S 2$, Rebecca, a member of Clem's new group, gives birth to a baby boy and dies shortly after. Rebecca reanimates as a zombie with the baby in her arms and Clem must save him from her. The player can choose to have Clem shoot Rebecca and take the baby - if not, Kenny will shoot her - and from that moment on, Clem becomes the baby's adoptive mother and names him AJ (see Figure 3). Even though she is only eleven years old, Clem takes responsibility for AJ, though her role as mother is fraught with difficulty. Kenny sees AJ as 
giving him another chance at fatherhood. ${ }^{2} \mathrm{He}$ admits that he failed to raise his late son like he should have and vows not to make the same mistakes raising AJ. However, following Kenny's death later in the episode, Clem becomes AJ's sole parent.

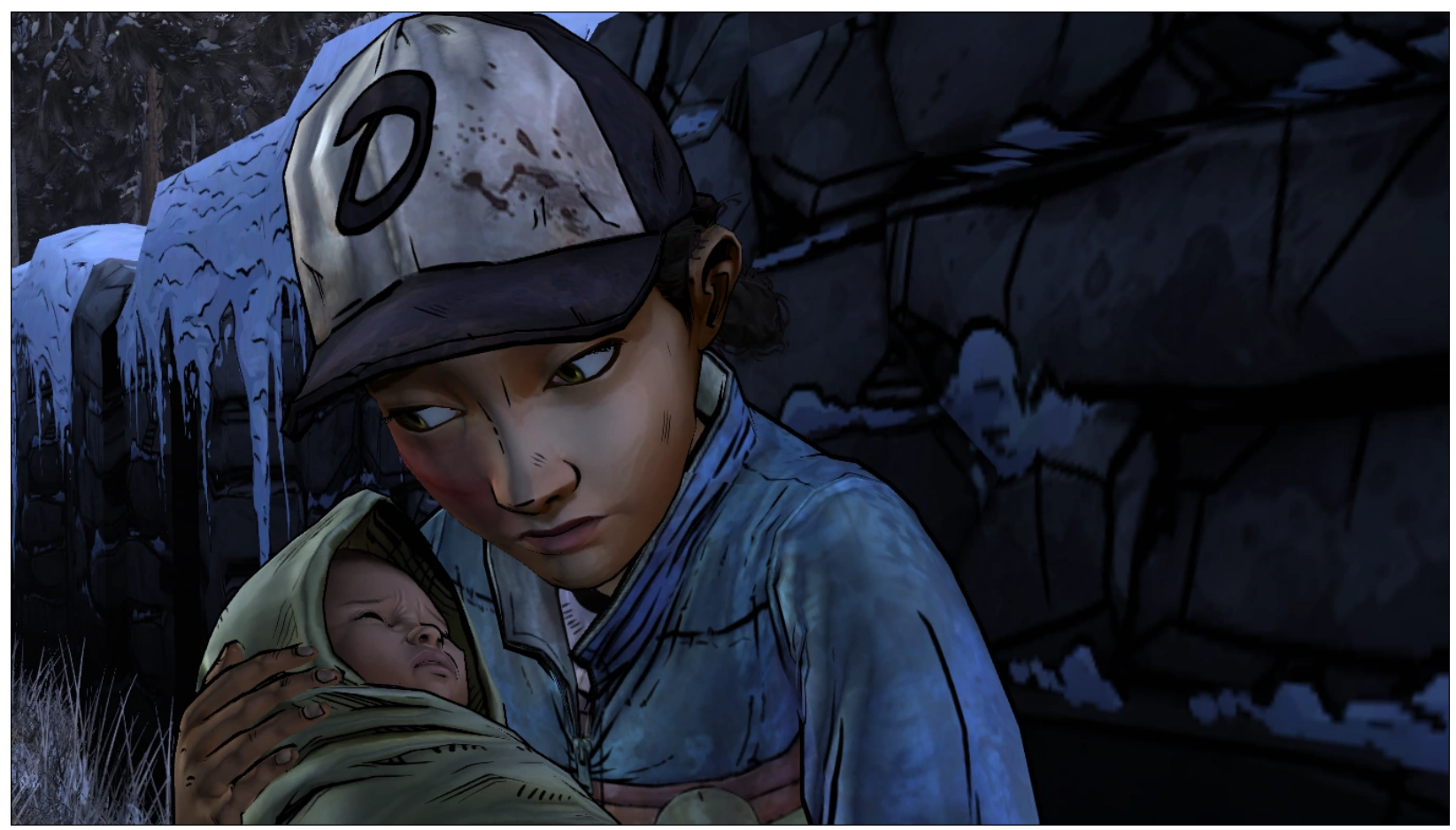

Figure 3: Clem and AJ. Screenshot taken from The Walking Dead: Season Two

Although the player-character is Javier (Javi) in A New Frontier (hereafter S3), Clem is present throughout most of the story. She is not, however, with AJ when Javier meets her. Through Clem's dialogue and a series of flashbacks, players learn that she and AJ joined up with a community called the New Frontier, but when AJ got sick, they refused to waste their medicine on him. Clem stole the medicine for AJ but was caught and exiled by the community's leader. They told her that she was too young to look after AJ and would not let her take him with her into exile. She was convinced they simply murdered AJ, or let him die from his illness, seeing him as nothing but a burden. Due to the trauma of losing her adoptive child, as well as life in a post-apocalyptic world, thirteen-year-old Clem became hardened, bitter, and wary. She no longer trusts strangers and has fully embraced the violence necessary to survive in a world full of both zombies and dangerous humans. Players are shown again and again that humans, rather than zombies, actually pose the biggest threat to other humans. This is common in zombie narratives, as Toby Smethurst and Stef Craps (2014) point out in their analysis of The Walking Dead:

In much of the best zombie-themed media ... the undead are not necessarily the primary antagonists but can instead function as a catalyst for conflicts between the survivors, thus exposing the barbarism of human beings toward one another when they are put in life-threatening situations.

This barbarism is perhaps why family is such a central theme in much post-apocalyptic media - 
within these worlds of social breakdown and chaos, in which violence is the only viable currency and survival means everything, family members (whether blood-related or chosen) are framed as the only people you can trust.

The complicated dynamics of familial bonds are explored at length in $S 3$, and the familial drama played out between Javi, his estranged brother David, and his brother's family is intertwined with Clem's own maternal story. She discovers that the leader of the New Frontier (who was Javi's long-lost brother David) did not murder AJ after exiling her. AJ recovered from his illness without medicine, and David tried to raise him for a short time. According to David, AJ was a misbehaved child, so he sent him to be raised by others on a ranch. With a renewed sense of purpose, Clem sets off at the end of the game to find AJ, who she sees as the only family she has left.

Although Clem is not actively parenting in this season, players are shown several scenes and flashbacks offering glimpses into her development as a mother. These moments all underscore the point that Clem feels like a mother, and wants to be one, even if she is only a child herself. For example, during her first encounter with a member of New Frontier when she and AJ were on their own, a woman tells Clem "you seem kind of young to be a mom. What are you, thirteen? Damn, you're a child yourself" and Clem, clearly irritated, responds "I'm old enough to put a bullet in you!" $(S 3)$. Any conversation which casts doubt on her maternal capabilities is clearly not one Clem wants to have. As another example, after witnessing an argument between David and his son Gabe, Clem recognizes how difficult parenting can be when she says to Javi: "I know Gabe doesn't see it, but David really is trying to look out for him. He's not doing the best job, but... No one gives you a rulebook to raise a kid" (S3; see Figure 4). The player can choose to have Javi respond with "not everyone's like you Clem, not everyone wants to take care of a baby" $(S 3)$. Clem replies with "after you put in all that work, so much of your heart..." Although she trails off, her words indicate her own self-identification as a parent (S3). 


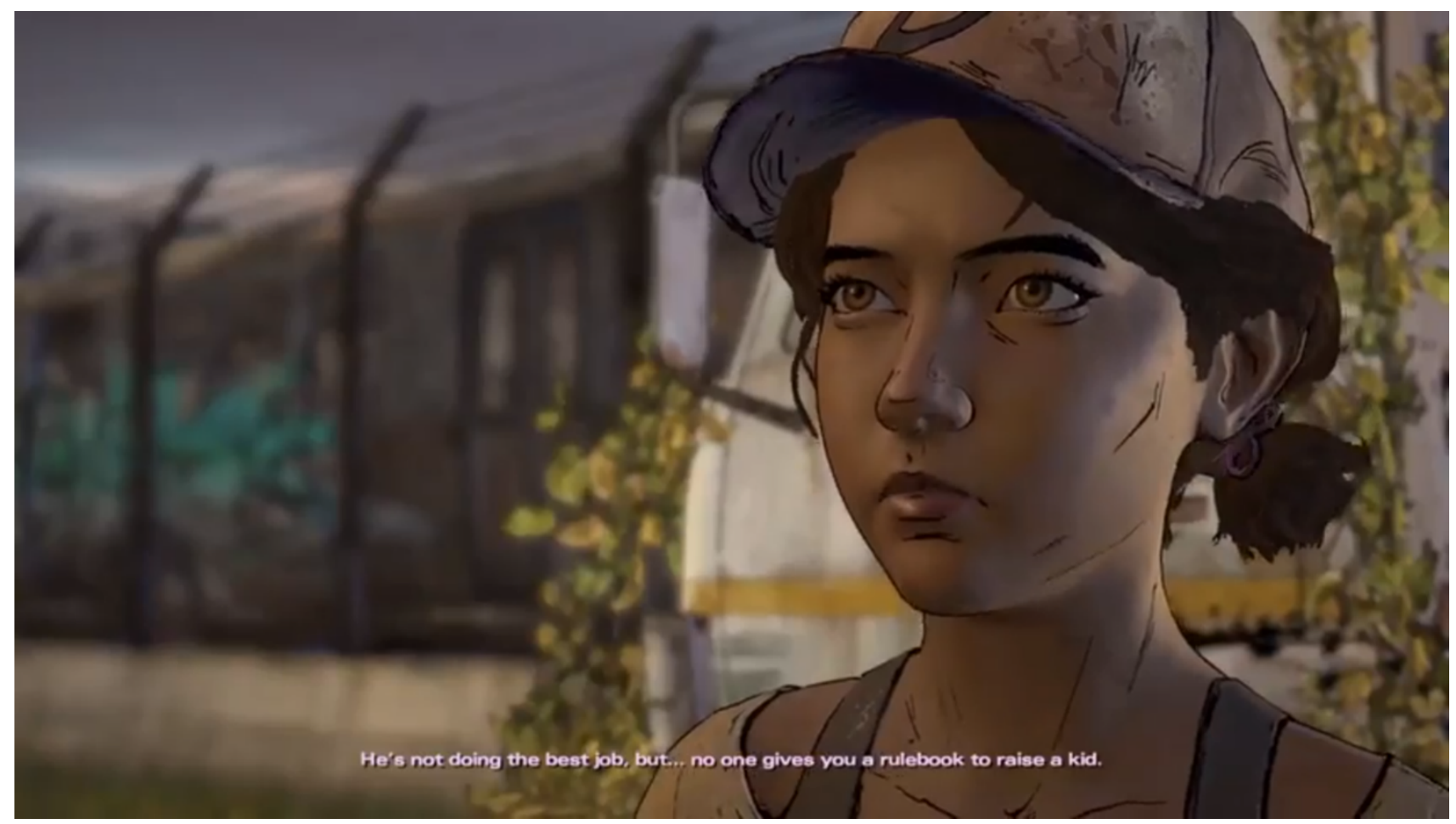

Figure 4: Clem. Screenshot taken from The Walking Dead: A New Frontier

Another example occurs in a conversation between Clem and Javi: although Javi is not a fatherfigure for Clem, he is tasked with explaining menstruation to her in one memorable scene. Clem knows that it is normal, but no one ever explained to her what it means, so the player can choose for Javi to tell her that her body is changing and that it means she could become a mom if she wanted. This moment of care is reminiscent of the way Lee interacted with Clem when he cut her hair - slightly awkward due to stereotypical masculine discomfort with feminine topics but enacted with kindness and honesty. However, the most notable element in this scene is Clem's reaction to Javi's explanation: "Funny. I already felt like a mom. Kenny used to say I was a natural-born mother" (S3; see Figure 5). This statement is followed by a flashback in which players see Clem, Kenny, and AJ around a campfire. Kenny tells Clem that she's the only "mama" that AJ has, and that she is "protective, loving, caring... All the things a good parent needs to be and all at your age" (S3). Clem already felt like a mother, regardless of her reproductive biological functions and age, and she believed, and was told, that she was good at it. 


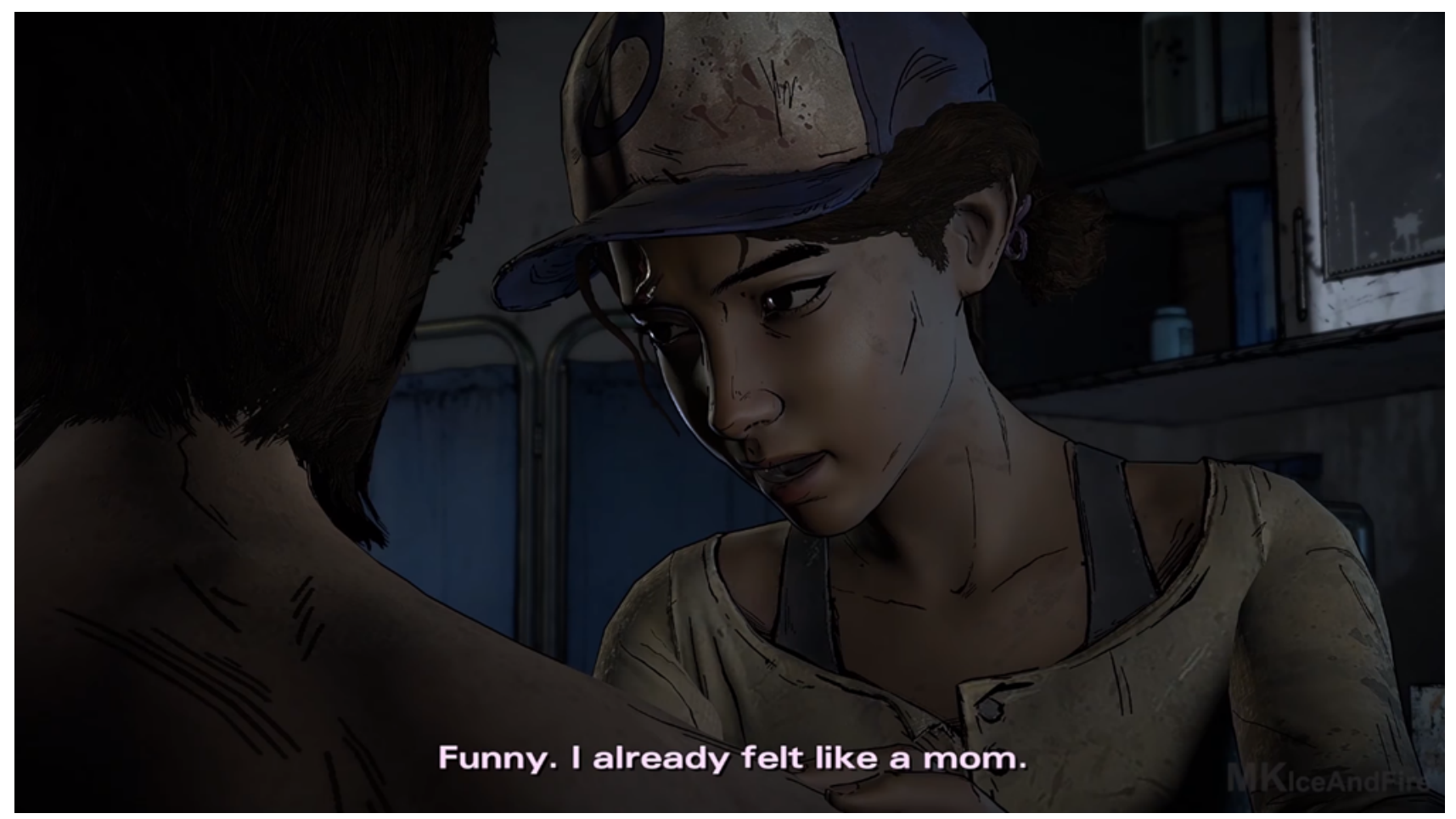

Figure 5: Clem. Screenshot taken from The Walking Dead: A New Frontier

Clem remembers this scene with bittersweet fondness: she has internalized her maternal role but has lost her child. However, once she discovers that AJ is alive, Clem is consumed with finding him. He is her primary motivation and she is even willing to commit murder to learn his location. Her quest to find her son drives her, and the scenes in which players are shown an enraged Clem (as opposed to her appearing fearful or just killing zombies because she must) mostly occur when others take her son away from her or threaten him. This is common to violent paternal narratives, such as the films discussed by Hamad (2013), the quintessential vengeful father film Taken (2008), as well as the dadified games mentioned earlier. However, male characters enact violent agency for many different reasons in popular culture, whereas women's rage is often only portrayed as justified (albeit controversial) if it takes the form of either rape revenge, as in I Spit on Your Grave (1978), Thelma and Louise (1991), or The Girl with the Dragon Tattoo (2011), or maternal rage, as in The Handmaid's Tale and A Quiet Place.

According to Sjoberg and Gentry (2007), the maternal rage narrative positions women's anger and violence as emotional and irrational: she is so overtaken by grief and/or protective instincts, like a 'mother bear,' that she loses control of her own actions (p. 32). In this positioning, the violent woman is "driven by rage because of maternal losses" and "motherhood gone awry" (Sjoberg \& Gentry, 2007, p. 34; p. 13). This is presented in contrast to "calculated retaliation," which is a more rational, logical, and therefore masculine-gendered form of vengeance (p. 34). Although acts of violence are often a result of player choice in $T W D$, Clem's willingness to commit murder to find AJ occurs in $S 3$ when she is an NPC and so her actions are out of the player's control. A suicidal character wants Javi to inject him with a lethal chemical in exchange for information on AJ's whereabouts. Clem insists that he go through with it, as she sees it as her only chance to find her son. The player can choose to do it or not, and if they choose not to, 
Clem gets angry and Javi responds with "I'm sorry Clem. We can't do this" (S3). Clem declares "No I have to. If you won't, I will" but Javi grabs her arm and refuses to let her go, even when she tries to pull away $(S 3)$. He paternalistically assures her that "We'll find AJ. Just not this way" and she angrily declares that "There is no other way!" (S3). In this scene, Clem is positioned as the irrational, desperate example of "motherhood gone awry" while Javi - an older man - is presented as the calm and moral voice of reason.

Clem's actions in that scene, along with her flashbacks to her time with AJ and her dialogue about her maternal feelings, solidify her role as a mother-figure. Although Clem is given moments of non-maternal character development, such as carrying out conversations that are not about AJ - reminiscing about Lee, developing a relationship with Gabe, and demonstrating her own maturity, resourcefulness, and skill - her presence in $S 3$ primarily serves to inform players that she is a mother who is willing to do anything for her son. While Javi's story is centralized in $S 3$, Clem's role as an NPC sets the stage for the final season in which she is more fully developed as a mother-figure.

\section{The Walking Dead: The Final Season (in which Clem is the new Lee)}

The Final Season (hereafter S4), which takes place roughly three years after the end of S3, opens with Clem driving a car and five-year-old AJ sitting in the back seat. Throughout the series, Clem has always referred to AJ as "goofball" but he complains when she does so in this scene he considers himself too old for such a childish nickname. After years on the road with her, AJ wants to grow up and Clem has to accept that - in this sense, this conversation could be taking place between any parent and child, regardless of setting. Like any five-year-old, AJ is restless in the backseat, bored and hungry. The player can choose to have Clem give him some potato chips - the last of their food. When she gives him the snack, he asks "what about you?" but Clem shrugs off her own hunger, sacrificing for her son $(S 4)$.

As $S 4$ progresses, the parallels between Clem and Lee are clear - nearly every choice the player makes while with AJ has to do with his wellbeing. However, while Lee was tasked with caring for a little girl who was already eight years old when they met, Clem raised AJ almost entirely on her own - except for the months they were apart - a child born into a broken, hostile world of monsters and raiders. Perhaps because of the dangers he must always face, AJ has behavioural issues which are left mostly unexplained: he hates being approached from behind and will attack anyone who does, he bites strangers for no reason, and he struggles to differentiate between moral and immoral forms of killing (that is, killing zombies versus killing humans). This is relevant because AJ's behaviour actively endangers Clem, straining their relationship and challenging Clem's commitment to her son. For example, Clem and AJ join an all-children group surviving in a school they use as a fortress, and Clem is forced to mediate between AJ and the others. They all like Clem - she is capable, friendly, and good at killing zombies - but it takes effort on the part of the player to get them to forgive AJ's transgressions. Although the two find a home for themselves in the school with the other children, the situation quickly darkens as they discover that the leader of the group, a teenager named Marlon, was trading children to raiders for protection. When his secret is discovered, he murders a girl and tries to kill Clem. After a tense stand-off, Clem is able to talk Marlon down, get him to drop his gun, and admit his 
wrongdoings. However, as soon as he drops his gun, AJ shoots him in the head with the pistol he always keeps tucked into his pants. The first episode ends with this shocking scene, and a large part of the next episode sees Clem paying the price for AJ's mistake and trying to explain to him why his actions were wrong.

One of the other characters, Louis, calls AJ a murderer after he shoots Marlon and demands of Clem, "what the fuck did you teach this kid?!" (S4). This moment is a reminder that Clem raised AJ on her own, and so had to teach him to survive from a very young age. Periodically throughout the season, she repeats important lessons with AJ: to breathe when he feels scared or angry but also to "always aim for the head" (S4). While this is a vital lesson when fighting zombies, AJ has clearly internalized this lesson for any perceived threat. He considered Marlon a monster for what he did, so he shot him like he has shot countless other monsters. Clem tries to explain to AJ that shooting humans is wrong if they are not a threat, he counters by reminding her that she shot Lee even though he was handcuffed. Although Clem is haunted by the memory, she does not regret her actions and so explains that it was a mercy killing to prevent Lee from reanimating as a zombie. However, Clem has killed many people throughout the series, usually in self-defence, and so also taught AJ to kill at a young age. As such, the game makes it clear that Clem is not necessarily an ideal role model - as players saw in $S 3$ when she was willing to commit murder to find $\mathrm{AJ}$ - and that being a parent is not easy in a zombie-infested world.

Although Clem suffers because of AJ's behaviour - they are kicked out of the group and forced to once again survive on their own, at least temporarily - she never considers blaming or abandoning him. While her compassion is inspiring, it is also perceived as a weakness by the adults she encounters. For example, after being kicked out of the school, AJ and Clem run into Lilly, a character from $S 1$, and she observes that Clem is behaving just like Lee - saddling herself with the burden of a child. Lilly tells Clem that she will end up dead just like Lee if she repeats his mistakes: "Your little boy there. You'll die protecting him ... Eventually he'll slow you down" (S4). Lilly argues that Lee would be disappointed to know that the girl he sacrificed himself to save is risking her life by caring for another, but players can have Clem retort that Lee would be proud to see she is taking care of a child, just like him. Just as Lilly assumed Lee was a 'better' person in $S 1$ because he had Clem to protect, she now assumes Clem is 'weaker' for the same reason. While this is not quite the same as characters in past seasons assuming Clem was too young to look after a child herself, it does imply that she would be unable to successfully care for both herself and AJ in such a hostile world. Interestingly, all the adults encountered in this season are violent and dangerous while the children are generally kind. They understand the value of caring for those weaker than themselves since they were abandoned by almost all the adults at their school when the zombie outbreak happened and have been fending for themselves ever since. Accordingly, none of the children question Clem and AJ's relationship or try to suggest that she is too young to be a capable mother.

Although she is not preoccupied with her own young age - Clem has not considered herself a 'child' for a long time - she does often question and doubt herself as a mother. This is primarily because her actions shape AJ, just as Lee's actions served as lessons for Clem in $S 1$. In Episode 3, "Broken Toys," the player is explicitly informed that AJ learns from their actions with the statement "AJ looks to you for guidance in this world" (S4). This responsibility makes Clem anxious and unsure of herself, feelings which manifest in the form of a dream in which she 
speaks to Lee:

Lee: You're in my shoes now, raising a kid. Think you got a handle on it?

Clem: I don't know - the world's awful... I don't know if I'm teaching him right.

Lee: I don't know of anyone who could do it better.

Importantly, although there is a lot of violent action in the final season, there are also several moments of teaching, caretaking, and tenderness between Clem and AJ. For example, AJ asks Clem how to get rid of his trauma, admits how terrified he is of losing her, and they say "I love you" to each other and hug (see Figure 6). These moments echo the interactions between Lee and Clem in S1 and send the message that Clem is a good mother, just as Lee was a good father.

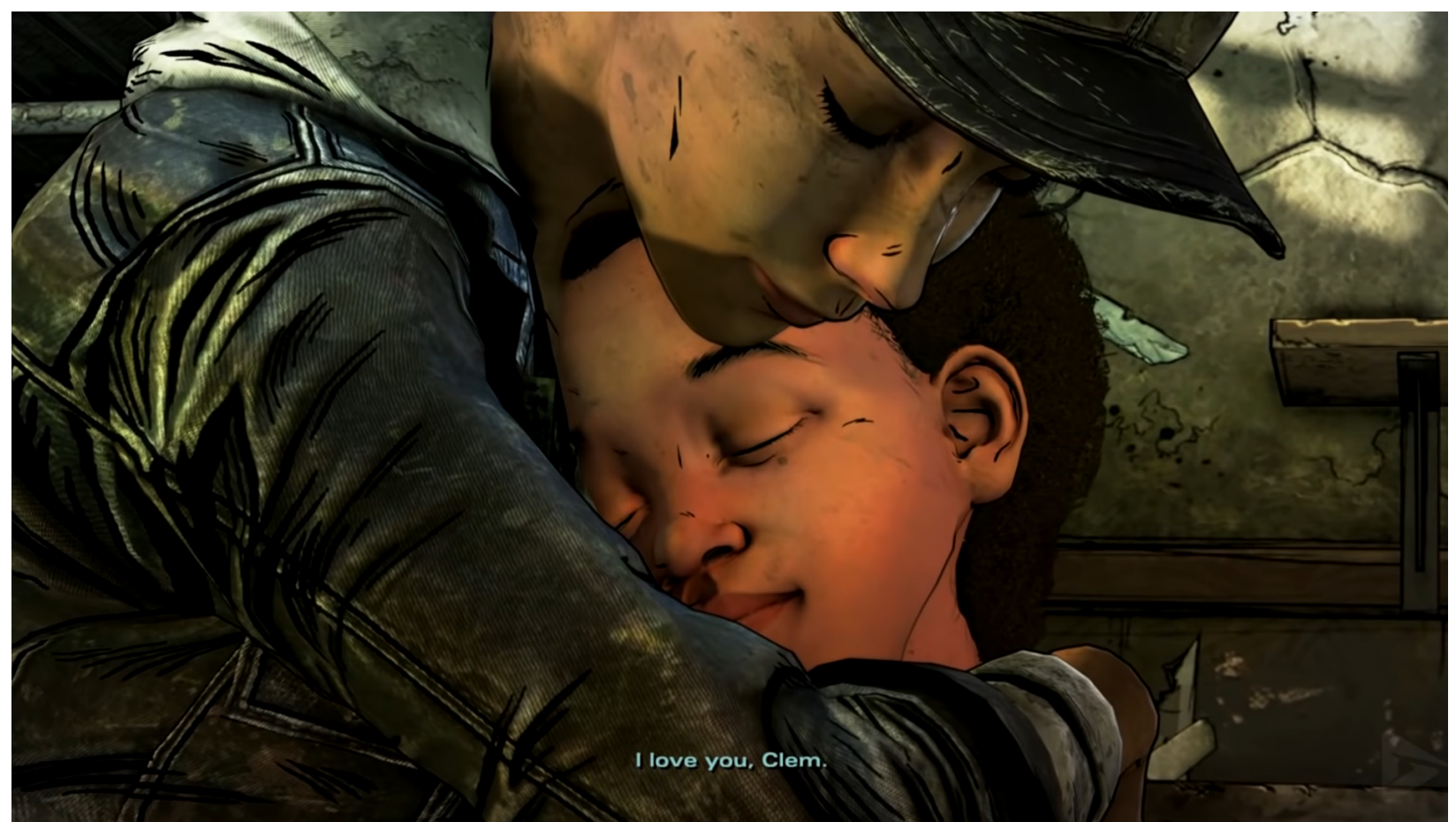

Figure 6. Clem and AJ share a tender moment. Screenshot taken from The Walking Dead: The Final Season

This message is particularly important because $T W D$ series very rarely portrays biological parent-child relationships, perhaps due to the realistic assumption that families would be torn apart by the zombie apocalypse. However, this contrasts trends in other recent post-apocalyptic or dystopian media, as the parent-child relationships portrayed in the films and television shows previously discussed are almost all biological. Bird Box is the only exception to this, as one of the main character's children is adopted while the other is biological. However, like Mad Max: Fury Road, The Handmaid's Tale, and A Quiet Place, Bird Box does centralize the experiences of women who are pregnant and give birth. In this sense, these films still associate maternity with biology. This is what Shelley Park (2006) identifies as "a pronatalist perspective" which "defines motherhood as a natural, biological phenomenon including both a gestational and genetic connection to one's child" (p. 202). It is also a heteronormative and "reprosexual" perspective, meaning that adoptive motherhood is therefore positioned as queer (Park, 2006, $\mathrm{p}$. 
202). TWD acknowledges the perceived deviancy of adoptive motherhood in the ways Clem's role as mother is continually challenged by others, yet it pushes back against this pronatalist perspective by having Clem insist that she felt like a mother long before she was physically able to reproduce, by having other characters like Kenny refer to her as a mother, and by demonstrating and reaffirming her parental role throughout the series. Park reads the adoptive maternal body as a potential site of resistance against essentializing, heteronormative, and biological determinist conceptions of motherhood. I argue that Clem embodies this potential site of resistance, especially given the dominance of biological parenthood in post-apocalyptic media which, except for Bird Box, reinforces the assumption that people only fight for or sacrifice themselves for their biological children.

Although this final season made it clear that Clem is as much a mother as Lee was a father, it also highlights the fact that Clem is not just a mother and $\mathrm{AJ}$ is not the only important person in her life. Just as Lee and Javi had relationships with characters other than their children, Clem develops relationships with other people she meets. In $S 3$ there appeared to be a blossoming romance between Clem and Gabe, which the player-character observed through Javi's perspective. In $S 4$, players can choose to initiate a romantic relationship between Clem and one of two teenagers at the school: Louis or Violet. While this relationship is optional, it underscores the point that Clem has other relationships and other characteristics that define her. That players can have Clem initiate a relationship with another girl - even if it is optional content - is particularly important because of the series' overall theme of alternative familial bonds and adoptive parenthood. Although Park (2006) reads adoptive motherhood as queer primarily in the sense that it opens up "the possibilities for more radical feminist conceptions and practices of mothering," she also notes that the experiences of adoptive mothers provide a perspective by which we can "normalize queer motherhood" (p. 204). Players who choose to have Clem initiate a romantic relationship with Violet are therefore able to enact the role of queer adoptive mother a role which is very rarely (if ever) centralized in games or in popular culture more broadly. This portrayal is especially rare given that Clem is a woman of colour in an interracial lesbian relationship.

Clem's relationship with AJ is, however, the primary focus of her narrative arc, just as Lee's relationship with Clem was the focus of the first season. In this sense, just as $S I$ can be read as a dadified game due to its centralization of a paternal narrative, the series as a whole - or at least seasons $2-4-$ can be in turn read as a momified narrative. Indeed, Clem is clearly presented as echoing Lee's approach to parenting: comparing the cover art for $S 1$ and $S 4$ makes the similarities clear and demonstrates that the developers purposefully designed Clem to become the new Lee and follow in her father-figure's footsteps (see Figure 7). 


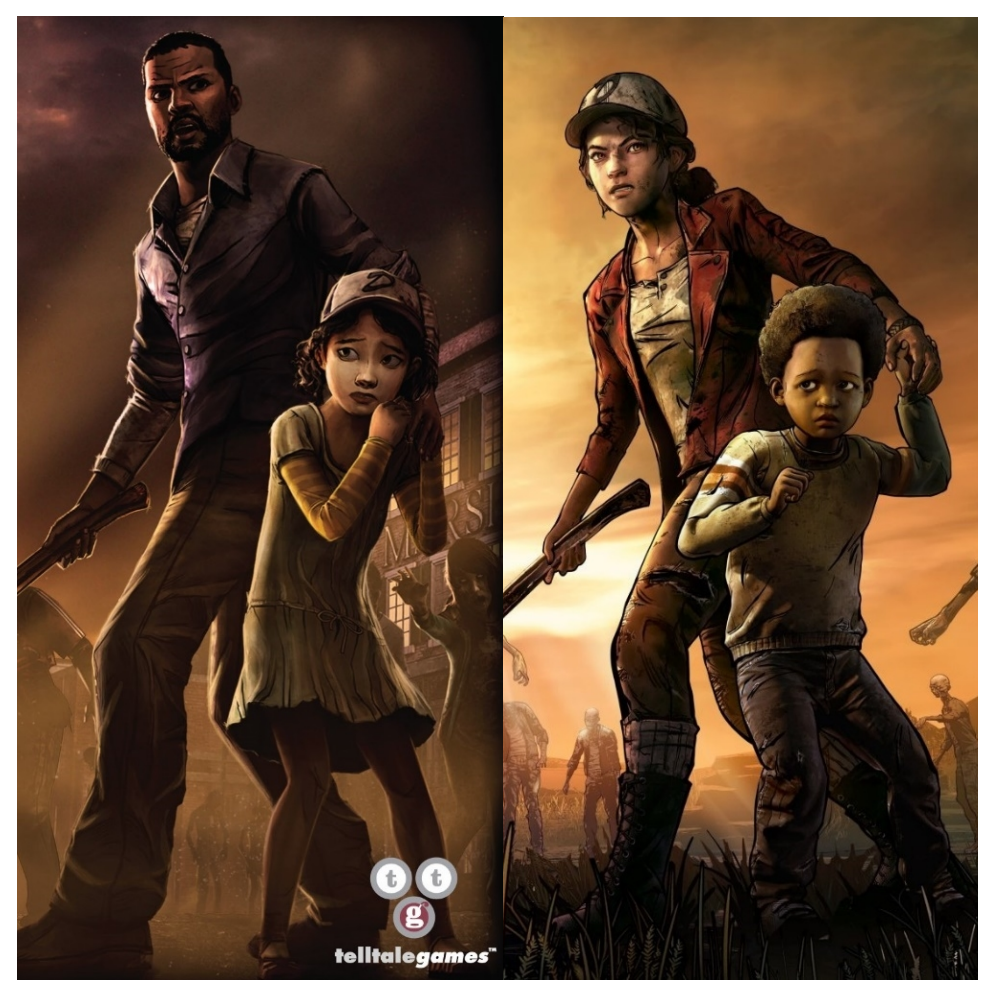

Figure 7: Screenshots of the cover art from The Walking Dead: Season One and The Walking Dead: The Final Season

\section{Conclusion: A Momified Game}

TWD series as a whole follows Clem's development from a child needing the care and protection of others into a capable and dedicated mother-figure. Although caring for a child while still a child herself certainly puts Clem at risk, she is drawn to the idea of family and has considered AJ her family since his birth. Aggressive, violent, adult characters like David and Lilly see her bond with AJ as a weakness, while Clem insists on the importance of family and is proud to follow in Lee's footsteps in caring for a child in need.

Although the series assumes certain normative truths about 'natural' and 'good' motherhood, it emphasizes that parenthood has nothing to do with blood relations or reproductive functions and leaves the nuances of parenting up to player choice. For example, players can encourage AJ to be more or less violence-oriented, but Clem is still framed as a good mother regardless of player choice because both compassion and violence are considered legitimate responses to such a dangerous world. However, as with Lee's relationship with Clem, several moments of care and tenderness are non-optional, such as when Clem and AJ say "I love you" to each other in $S 4$. Although she is considered a good mother, she is not presented as a perfect one, since she loses $\mathrm{AJ}$, raises him to be a ruthless killer like her, and fails to stop him from committing murder. Clem questions her own abilities as a mother, but unlike Joel from The Last of Us or Booker from BioShock Infinite, Clem does not attempt to undermine AJ's agency. She teaches him and reprimands him while still recognizing his autonomy and remaining by his side regardless of his mistakes. 
However, Clem's maternal role in the series could be read as problematic; she is called a 'natural' mother by older male characters who themselves 'failed' at fatherhood and she forgoes her own childhood and safety in order to care for a baby, and so is presented as self-sacrificing. This is particularly important to note because she is a woman of colour, so her story could fit into the long history of women of colour caring for other peoples' children as household slaves or as nannies and their continued portrayal as such in popular culture (Sewell, 2013). However, Clem took on a maternal role of her own volition, and although she had many opportunities to abandon AJ or let others take him, she refused to stop fighting for him. In addition, while examples of strong mothers who fight for their children in extreme situations are becoming more common in popular culture - such as in The Handmaid's Tale, Mad Max: Fury Road, A Quiet Place, and Bird Box, as previously discussed - they are all white women and almost all the biological mothers of their children. That $T W D$ tells the story of a (potentially) queer woman of colour who voluntarily takes on the role of mother (and protector and teacher) of another woman's baby at an extremely young age and never stops fighting for him, teaching him, and protecting him, makes it unique as a video game and in Western popular culture more broadly.

While TWD is a dadified game series in that two of the three playable characters - Lee and Javi are father-figures, it is also a rare example of a momified game. Although there are a few other games which feature maternal protagonists - such as Fallout 4 (2015) if players choose a female avatar - TWD is notable in that it features an unconventional yet generally positive mother-figure who balances fighting skill with love and care. Since she is a 'strong female character' who is also young, a person of colour, potentially queer, and an adoptive mother-figure, she presents a clear alternative to the kind of protagonist that has long dominated narrative-heavy video games (straight white men in their mid-thirties or older) and an important example of how games can centralize more diverse identities. So while scholarship and other critical writing on TWD has discussed it within the context of the dadification of games - albeit as a healthier, more nuanced portrayal of fatherhood - in examining the series as a whole and focusing on its main protagonist, Clementine, it becomes clear that it is also a momified game. TWD is Clem's story, which is remarkable given that the game industry so rarely tells stories of mothers or women of colour. While it is a familiar story of survival in a violent, broken, post-apocalyptic world, it is also a story of kindness, tenderness, and care which highlights the strength of alternative and unconventional familial bonds that have nothing to do with blood and everything to do with love. As Clem declares in S3, "family means something different now. You have to make it for yourself."

\section{References}

Bell, K., Kampe, C., \& Taylor, N. (2015a). Me and Lee: Identification and the play of attraction in the walking dead. Game Studies, 15(1). Retrieved from http://gamestudies.org/1501/articles/taylor

Bell, K., Kampe, C., \& Taylor, N. (2015b). Of headshots and hugs: Challenging hypermasculinity through the walking dead play. Ada: A Journal of Gender, New Media, and Technology, 7. Retrieved from https://adanewmedia.org/2015/04/issue7bellkampetaylor/ 
Bennett, B. (2018). The undying ideologies of race and gender: The zombie apocalypse in Telltale's the walking dead: Season one. Feminist Media Studies, 19(5), 637-650. https://doi.org/10.1080/14680777.2018.1457068

Besson, L. (Dir.). (2008). Taken. EuropaCorp.

Bethesda Game Studios. (2015). Fallout 4. Bethesda Softworks. Microsoft Windows.

Bier, S. (Dir.). (2018). Bird box. Netflix.

Blythe Adams, M. (2018, May 30). Pater ominopotens: The father as saviour in games culture. Talk given at the Canadian Games Studies Association's Annual Conference. Regina, Canada.

Brice, M. (2013, August 15). The dadification of video games is real. Alternate Ending. Retrieved from http://www.mattiebrice.com/the-dadification-of-video-games-is-real/

Campbell, C. (2016, July 7). Where are all the video game moms? Polygon. Retrieved from http://www.polygon.com/features/2016/7/7/12025874/where-are-the-video-game-moms

Ecenbarger, C. (2016). Comic books, video games, and transmedia storytelling: A case study of the walking dead. International Journal of Gaming and Computer-Mediated Simulations, $8(2), 34-42$.

Fincher, D. (Dir.). (2011). The girl with the dragon tattoo. Metro-Goldwyn-Mayer Pictures.

Gray, K. (2017, May 9). Why is motherhood so poorly portrayed in video games? The Guardian. Retrieved from https://www.theguardian.com/technology/2017/may/09/video-gamesmotherhood

Grayson, N. (2013, February 28). Telltale on walking dead season 2 and beyond. Rock Paper Shotgun. Retrieved from https:/www.rockpapershotgun.com/2013/02/28/telltale-onwalking-dead season-2-and-beyond/

Guerrilla Games. (2017). Horizon zero dawn. Sony Interactive Entertainment. PlayStation 4. Hamad, H. (2013). Hollywood fatherhood: Paternal postfeminism in contemporary popular cinema. In J. Gwynne \& N. Muller (Eds.), Postfeminism and contemporary Hollywood cinema (pp. 99-115). Palgrave Macmillan.

Irrational Games. (2013). BioShock infinite. 2K Games. Microsoft Windows.

Joho, J. (2014, November 2). The dadification of video games, round two. Kill Screen. Retrieved from https://killscreen.com/articles/dadification-videogames-round-two/

Krasinski, J. (Dir.). (2018). A quiet place. Platinum Dunes.

Manuel, R. (2013, February 5). How adventure games came back from the dead. PC World. Retrieved from http://www.pcworld.com/article/2026802/how-adventure-games-cameback-from-the dead.html

Miller, B. (Creator). (2017-2018). The handmaid's tale. Hulu.

Miller, G. (Dir.). (2015). Mad max: Fury road. George Miller.

Myers, M. (2013, July 30). Bad dads vs. hyper mode: The father-daughter bond in videogames. Paste. Retrieved from http://www.pastemagazine.com/articles/2013/07/hyper-mode.html

Naughty Dog. (2013). The last of us. Sony Computer Entertainment. PlayStation 3.

Park, S.M. (2006). Adoptive maternal bodies: A queer paradigm for rethinking mothering? Hypatia, 21(1), 201-226.

Reeves, B. (2012, November 26). Lord of the dead: An interview with Robert Kirkman. Game Informer. Retrieved from http://www.gameinformer.com/b/features/archive/2012/11/26/lord-of-the dead-aninterview-with-robert-kirkman.aspx

Santa Monica Studio. (2018). God of war. Sony Interactive Entertainment. PlayStation 4. 
Scott, R. (Dir.). Thelma and Louise. Metro-Goldwyn-Mayer.

Sewell, C.J.P. (2013). Mammies and matriarchs: Tracing images of the black female in popular culture 1950s to present. Journal of African American Studies, 17(3), 308-326.

Shyamalan, M.N. (Dir.). Signs. Touchstone Pictures.

Sjoberg, L., \& Gentry, C.E. (2007). Mothers, monsters, whores: Women's violence in global politics. London: Zed Books.

Smethurst, T. \& Craps, S. (2014). Playing with trauma: Interreactivity, empathy, and complicity in the walking dead video game. Games and Culture, 10(3). Retrieved from http://journals.sagepub.com/doi/abs/10.1177/1555412014559306

Smith, C. (2014, November 10). Gaming's mom problem: Why do we refuse to feature mothers in games? Polygon. Retrieved from http://www.polygon.com/2014/11/10/7173757/mothers-in-video-games

Spielberg, S. (Dir.). (2002). Minority report. $20^{\text {th }}$ Century Fox.

Spielberg, S. (Dir.). (2005). War of the worlds. Amblin Entertainment.

Stang, S. (2016a, December 7). Controlling fathers and devoted daughters: Paternal authority in bioshock 2 and the witcher 3: Wild hunt. First Person Scholar. http://www.firstpersonscholar.com/controlling-fathers-and-devoted-daughters/

Stang, S. (2016b). Player agency in telltale games' transmedia and cross-genre adaptations. Cinephile 11(3): Adaptations, Translations, Permutations. http://cinephile.ca/wpcontent/uploads/Cinephile-11.3-Finall.pdf

Stang, S. (2017). Big daddies and broken men: Father-daughter relationships in video games. Loading... 10(16): CGSA Double Issue. http://journals.sfu.ca/loading/index.php/loading/article/view/180

Stang, S. (2018). Big daddies and their little sisters: Postfeminist fatherhood in the bioshock series. In J. Aldred \& F. Parker (Eds.), Beyond the sea: Critical perspectives on bioshock (pp. 30-57). McGill-Queens University Press.

Sulimma, M. (2014). Did you shoot the girl in the street? - On the digital seriality of the walking dead. Eludamos, 8(1), 83-100. http://www.eludamos.org/index.php/eludamos/article/view/vol8no1-6

Tasker, Y. (2008). Practically perfect people: Postfeminism, masculinity and male parenting in contemporary cinema. In M. Pomerance (Ed.), A family affair: Cinema calls home (pp. 175-187). London: Wallflower Press.

Telltale Games. (2012). The walking dead: Season one. Microsoft Windows.

Telltale Games. (2013-2014). The walking dead: Season two. Microsoft Windows.

Telltale Games. (2016-2017). The walking dead: A new frontier. Microsoft Windows.

Telltale Games. (2018). The walking dead: The final season. Microsoft Windows.

Totilo, S. (2010, February 9). The daddening of video games. Kotaku. Retrieved from http://kotaku.com/5467695/the-daddening-of-video-games

Voorhees, G. (2016). Daddy issues: Constructions of fatherhood in the last of ss and bioshock infinite. ADA: A Journal of Gender, New Media, and Technology, 9. Retrieved from http://adanewmedia.org/2016/05/issue9-voorhees/

Wallace, K. (2012, December 26). Creating Clementine. Game Informer. Retrieved from http://www.gameinformer.com/b/features/archive/2012/12/26/creating-clementine.aspx

Zarchi, M. (Dir.). (1978). I spit on your grave. Cinemagic Pictures. 
${ }^{1}$ Although the comics were adapted into a popular television series as well, the Telltale Games series is adapted directly from the comics, without overt influence from the show. This was done on purpose, as Telltale wanted more freedom in what they could do with the characters. For more on this, see Ecenbarger (2016).

2 Or perhaps more accurately, 'grandfatherhood,' as Kenny recognizes Clem (his daughterfigure) as AJ's mother-figure, while also identifying himself as the baby's father-figure. This speaks to the somewhat confused (or alternative) family dynamics presented in the game. 